\title{
Directional Volatility Spillovers Between Agricultural, Crude Oil, Real Estate, and Other Financial Markets
}

\author{
Stephanie-Carolin Grosche and Thomas Heckelei
}

\section{$9.1 \quad$ Introduction}

Portfolio diversification is a principal motive for financial commodity trading (Fortenbery and Hauser 1990). The fundamentals that drive the supply and demand of commodities largely differ from those of other financial assets, suggesting low or negative return correlations. And, like real estate, commodities can serve as an inflation hedge as their prices drive inflation, but holding commodities is not directly associated with inflation-threatened cash flows (Ankrim and Hensel 1993; Huang and Zhong 2013; Bodie and Rosansky 1980; Satyanarayan and Varangis 1996; Anson 1999; Gorton and Rouwenhorst 2006; Daskalaki and Skiadopoulos 2011).

The spread of electronic trading and the creation of commodity index-linked exchange-traded products (ETPs) or mutual funds have made commodity markets more accessible to financial portfolio managers (Conover et al. 2010; Daskalaki and Skiadopoulos 2011). Between 2002 and 2010, assets under the management of commodity ETPs grew from 0.1 billion to 45.7 billion US dollars (BlackRock 2011). Simultaneously, combined open interest for the Chicago Board of Trade (CBOT) corn, soybean, and wheat futures climbed from 0.7 million to 2.7 million contracts (CFTC 2013).

Attractive diversification benefits and facilitated inclusion in portfolios stimulated the use of agricultural commodities in both strategic and tactical portfolio management. While strategic portfolio management may maintain a fixed commodity share [e.g., 4-7 \% according to Greer (2007)], tactical portfolio management continuously resets portfolio asset weights due to cross-market arbitrage (Büyükşahin et al. 2010) or as a response to shocks or extreme regimes in selected markets

\footnotetext{
S.-C. Grosche $(\bowtie) \bullet$ T. Heckelei

Institute for Food and Resource Economics (ILR), University of Bonn, Bonn, Germany

e-mail: stephanie.grosche@ilr.uni-bonn.de
} 
(cf. Conover et al. 2010; Jensen et al. 2002). Particularly during financial crises, portfolio managers may shift weights to comparatively less risky and more liquid refuge assets, a phenomenon known as "flight-to-quality" or "flight-to-liquidity" (Beber et al. 2007). Such use of commodities has been suggested, for example, by Silvennoinen and Thorp (2013) and Chong and Miffre (2010), who proposed a shift out of equity and bond markets and into commodities during crisis periods. Finally, the need to meet margin calls in distressed markets may affect weights of all other portfolio assets, if a broad range of assets needs to be sold to obtain liquidity (Büyükşahin et al. 2010).

By any of these channels, tactical portfolio allocation may create or intensify linkages between commodity and financial markets, especially during financial crises. It may also affect linkages between agricultural and energy markets as both commodity groups are included in indices such as the Standard and Poor's (S\&P) GSCI or the Dow Jones UBS (DJ UBS) Commodity index, which are replicated by index-linked products and funds. In any case, volatility, rather than returns, is the more interesting linkage due to its closer relation to information flows (Chiang and Wang 2011; Cheung and Ng 1996). Also, the development of ETP assets suggests a steadily emerging financial interest and motivates the search for a gradual change rather than a sudden structural break in market linkages.

In this chapter, we analyze time-varying short-term volatility spillovers between (1) commodity and financial markets and (2) agricultural and energy markets with rolling volatility spillover indices as introduced in Diebold and Yilmaz (2012) for the period from June 1998 to December 2013. The analyses are based on rolling generalized forecast error variance (FEV) decompositions in a vector autoregressive (VAR) model and allow us to calculate gradually changing directional volatility spillovers between any pair of included assets over the entire observation period. Volatility is measured as the daily range, based on the difference between high and low prices (Parkinson 1980).

Our analysis contributes to existing research in several aspects. First, we investigated the volatility linkages between agricultural commodities and financial assets, which remain scarcely researched. Second, we included a broad market network rather than conducting a bivariate analysis, thereby specifically taking into account the potential substitution between commodity and real estate as a result of the subprime crisis and the aforementioned parallel characteristics between the two asset classes. This also aids the investigation of agriculture-energy linkages as commodity markets are part of the global financial market network; any bivariate relation may thus be affected by the state of third markets. Finally, we do not impose any structural breakpoints; our analysis also goes beyond comparing the selected periods (e.g., before and after the recent financial crisis or before and after the introduction of biofuel mandates), also examining the gradual structural changes.

The remainder of the chapter is structured as follows: The next section focuses on existing empirical evidence on commodity-financial and agricultural-energy linkages, which is followed by a brief description of the methodology. Subsequently, we present and discuss our modeling results and compare them to previous studies. The final section concludes the analysis. 


\subsection{Previous Empirical Results on Market Linkages}

Agriculture-energy market linkages via the use of crops in biofuel production or the use of energy as an agricultural production input are frequently researched. In comparison, research on commodity-financial market linkages is scarce and only recently gaining momentum (Chan et al. 2011).

\subsubsection{Agricultural-Energy Market Linkages}

We reviewed recent empirical studies which focused on volatility linkages and which covered at least part of the time period after the subprime crisis. ${ }^{1}$ The studies typically split their data sample at around either 2006, due to a hypothesized structural change in market linkages after the introduction of biofuel mandates, or 2008, reflecting the potential effects of the financial and food price crises. Most studies used daily data, while Gardebroek and Hernandez (2012) and Du et al. (2011) used weekly data.

To investigate volatility dependencies, Nazlioglu et al. (2013) and Harri and Hudson (2009) conducted Granger causality in variance tests (cf. Cheung and Ng 1996). Nazlioglu et al. (2013) found no linkages between the volatility of daily energy and agricultural spot prices before 2005. The only exception is wheat, which Granger causes the variance of crude oil in that period. Likewise, Harri and Hudson (2009) did not detect any linkages between the volatility of daily corn and crude oil futures prices in the period before 2006. For the period after 2006, Nazlioglu et al. (2013) found volatility spillovers from crude oil to corn and bidirectional spillovers between crude oil and soybeans and between crude oil and wheat. Harri and Hudson (2009) only discovered Granger causality in mean, but not in variance, from crude oil to corn.

Du et al. (2011) used bivariate weekly stochastic volatility models to analyze corn, wheat, and crude oil futures returns for the period 1998-2009. They detected increasing volatility transmission from crude oil to both corn and wheat as well as volatility transmission between corn and wheat in the later subsample 2006-2009.

Several studies employed multivariate GARCH models. Gardebroek and Hernandez (2012) estimated both BEKK and DCC trivariate GARCH models for weekly US corn, crude oil, and ethanol spot prices for the period 1997-2011. There are some short-run volatility spillovers from corn to ethanol but no significant volatility spillovers in the other direction. Structural break tests and subsequent sample splits showed that volatility persistence is stronger in all markets after 2008. TrujilloBarrera et al. (2011) estimated BECKK GARCH models with daily futures returns for US crude oil, ethanol, and corn for the period 2006-2011. Similar to Gardebroek and Hernandez (2012) they found that the volatility linkages between corn and ethanol increased after 2007, with significant volatility spillovers from corn to

${ }^{1}$ This remains a vibrant field of research. Any omissions are not deliberate. 
ethanol but only modest spillovers from ethanol to corn. But they did find strong volatility spillovers from crude oil to both corn and ethanol markets. Ji and Fan (2012) and Chang and Su (2010) employed bivariate E-GARCH models. Chang and $\mathrm{Su}$ (2010) used daily returns to examine the relationships between crude oil, corn, and soybean futures during the period 2000-2008. Before 2004, there were no significant volatility spillovers from crude oil to either corn or soybeans; however, this changed in the 2004-2008 period. Ji and Fan (2012) used daily returns of crude oil futures and several Commodity Research Bureau (CRB) indices for the period 2006-2010 and introduced the US Dollar exchange rate as an exogenous shock. They found that volatility spillovers from crude oil to the CRB crop index decrease after the subprime crisis.

\subsection{2 (Agricultural) Commodity-Financial Market Linkages}

We reviewed recent empirical studies that (1) covered at least part of the period of the subprime crisis and (2) also considered corn, soybeans, wheat, or a relevant commodity index in their sample. Most studies focused on the relationships between selected US commodities and equity markets. Other financial asset classes, especially real estate, are underrepresented. In the past, the emphasis was on return linkages, but volatility dependencies are moving into focus.

Volatility relations are also mostly examined using multivariate GARCH models. Gao and Liu (2014) used bivariate regime switching GARCH models for analyzing the weekly relationships between the S\&P 500 index and selected commodity indices from 1979 to 2010. The volatility linkages between the S\&P 500 and both the grains and energy indices only slightly increase in the few brief periods whereby the assets shared a high volatility regime. But regime switches in the energy index appeared more closely related to equity volatility than those in the grains index. Mensi et al. (2013) estimated bivariate VAR-GARCH models for pairs of indices for the period 2000-2011; the pairs consisted of the S\&P 500 and the following indices: daily wheat, beverage, gold, crude oil, and Brent oil price. Past volatility and unexpected volatility shocks to the S\&P 500 have significant effects on oil, gold, and beverage markets, but not on wheat markets. For commodity-foreign exchange relations, Ji and Fan (2012) found that volatility spillovers from the US Dollar index to the CRB crop index were weaker after the subprime crisis than before it; Harri and Hudson (2009) observed Granger causality in mean but not in variance from the US Dollar exchange rate to corn futures prices in the periods before and after 2006.

Diebold and Yilmaz (2012) used their volatility spillover indices to investigate volatility linkages between the DJ UBS Commodity index and the following over the period 1999-2010: the S\&P 500, US Treasuries, and the US Dollar index. They found a significant increase in linkages between the DJ UBS Commodity index and the other markets after the beginning of the subprime crisis. Volatility spillovers from the S\&P 500 to the commodity index occurred throughout the crisis, while the commodity index volatility spilled over into US Treasuries and the US Dollar index during the middle of and the end of the last decade. 
Multivariate GARCH models have also been used to investigate commodityfinancial return linkages. Using a bivariate DCC GARCH model for the period 1991-2008, Büyükşahin et al. (2010) found that negative weekly conditional return correlations between (1) the Standard and Poor's Goldman Sachs Commodity Index (S\&P GSCI), (2) its energy sub-index, and (3) the DJ UBS Commodity index and equities peaked during 2003-2004; the correlations also peaked to a lesser extent at the beginning of the subprime crisis. Correlations between the S\&P 500 and the S\&P GSCI agricultural index returns appeared unaffected by the crisis. Creti et al. (2013) used bivariate DCC GARCH models to examine the relationship between the daily S\&P 500 returns and (1) 25 sampled commodity spot returns, and (2) the CRB index for the period 2001-2011. While they found that dynamic correlations decreased during the subprime crisis for most of the sampled commodities, return correlations between crude oil and the S\&P 500 increase in times of increasing, and decrease in times of decreasing stock prices. In contrast, Silvennoinen and Thorp (2013), who used a bivariate DSTCC GARCH ${ }^{2}$ model with weekly data between 1990 and 2009, showed that conditional weekly return correlations of equities and two commodities (corn and soybeans) increased in the period 2002-2003, while correlations of equities and two other commodities (wheat and crude oil) peaked in mid-2008. Commodity-bond relations remain relatively constant. Similarly, results from the DCC GARCH model in Huang and Zhong (2013) for the days between 1999 and 2010 and for the months between 1979 and 2010 showed that conditional correlations of the S\&P GSCI and US bonds did not considerably increase during the subprime crisis. Yet, conditional rolling return correlations between the S\&P GSCI and equities increased from negative to strongly positive. In addition, mean-variance spanning tests revealed that the $S \& P$ GSCI, Real Estate Investment Trusts (REITs) and US inflation-linked securities each offered unique portfolio diversification benefits, suggesting relatively weak market linkages. Finally, Bicchetti and Maystre (2013) examined rolling window bivariate intraday return correlations of equities and several commodities (corn, wheat, soybeans, and crude oil) for the period 1996-2011. The authors found an increase in correlations between all sampled commodities and equity returns after September 2008, which declined again in 2011 only in the case of crude oil.

Thus, there are some indications of increased volatility or return linkages between agricultural and energy markets, and between commodity and financial markets around 2006-2008. But, in the case of the agricultural-energy correlation, results are rather mixed. In the case of the commodity-financial correlation, the strongest effects appear to exist between US equities and crude oil. In both cases, the time-dependent dynamics and the direction of influence remain unclear. The majority of the studies focused on using multivariate GARCH models and therefore have to restrict their investigation to a bivariate or at maximum trivariate model.

\footnotetext{
${ }^{2}$ Dynamic Smooth Transitional Conditional Correlation Generalized Autoregressive Conditional Heteroskedasticity model.
} 


\subsection{Description of the Methodology and Data}

Volatility spillover indices introduced by Diebold and Yilmaz $(2009,2012)$ allow a larger sample of asset markets to be included while permitting a time-dependent analysis of gradually changing volatility relations. Their computation requires externally calculating a volatility proxy variable, which is then used in the rolling VAR model estimation.

Given that there is no universally accepted best volatility measure (Engle and Gallo 2006), a choice has to be made based on informational content, interpretability, and statistical properties. We expect financial linkages between markets to mostly affect short-term volatility relations. Therefore, we used the range volatility proxy that was described in Parkinson (1980), which has also been shown to have superior statistical properties over the classical volatility proxy. The classical volatility proxy is calculated as the variance of daily returns, which may be associated with large, non-Gaussian measurement errors (cf. Parkinson 1980; Alizadeh et al. 2002; Chiang and Wang 2011). The range is calculated as:

$$
\operatorname{Range}_{i t}=0.361\left[\ln \left(\frac{\operatorname{high}_{i t}}{\operatorname{low}_{i t}}\right)\right]^{2},
$$

where high is the highest and low the lowest price observed on a trading day $t$.

\subsubsection{Data}

We use a sample of CBOT corn, soybeans and (soft red winter) wheat futures, New York Metal Exchange (NYMEX) WTI crude oil futures, the S\&P 500 US equity index, the Dow Jones Equity all REIT index, CBOT 10-year US Treasury Note futures, and the Intercontinental Exchange (ICE) Futures US Dollar index. The REITs index consists of all US publicly traded companies within the Dow Jones stocks indices that are classified and taxed as equity REITs. The US Dollar Index is a geometrically averaged index of exchange rates of a basket of currencies against the US dollar; the basket comprises the euro, Japanese yen, British pound, Canadian dollar, Swedish krona, and Swiss franc. ${ }^{3}$ Price and volume data were obtained from Bloomberg for trading days between 3 June 1998 and 31 December 2013. ${ }^{4}$ Missing observations were replaced by a linear interpolation. ${ }^{5}$ All futures prices are historical first generic price series, and expiring active futures contracts are rolled to the next deferred contract after the last trading day of the front month. ${ }^{6}$

\footnotetext{
${ }^{3}$ Weights are as follows: Euro: $57.7 \%$, Yen: $13.6 \%$, British Pound: $11.9 \%$, Canadian Dollar: $9.1 \%$, Swedish Krona: $4.2 \%$, Swiss Franc: $3.6 \%$.

${ }^{4}$ Data for the REIT index is not available prior to that period.

${ }^{5}$ Interpolation implemented with the MATLAB linear interpolation function.

${ }^{6}$ This corresponds to Bloomberg's "relative to expiration" rolling procedure.
} 


\subsubsection{Generalized Forecast Error Variance Decompositions}

The FEV decompositions split the FEV of the range of each asset $i$ included in a VAR model into shares stemming from own shocks and shares stemming from shocks to the range of another asset $j$. A VAR model with lag length $p(\operatorname{VAR}(\mathrm{p}))$ that consists of range observations for all assets is written as $y_{t}=A_{0}+A_{1} y_{t-1}+\cdots+$ $A_{p} y_{t-p}+v_{t}$, where $y_{t}$ is a $N \times 1$ vector of range volatilities and $N$ corresponds to the number of assets in the system. $A_{i}$ is a fixed coefficient $N \times N$ matrix (including intercept terms), and $u_{t}$ is a $N \times 1$ vector of white noise innovations, such that $E\left(u_{t}\right)=0, E\left(u_{t} u_{t}{ }^{\prime}\right)=\Sigma$ and $E\left(u_{t} u_{t-s}\right)=0$. The equivalent VAR(1) in matrix notation is given as $Y_{t}=c+A Y_{t-1}+U_{t}$, where

$$
\begin{gathered}
Y_{t}=\left[\begin{array}{c}
y_{t} \\
y_{t-1} \\
\vdots \\
y_{t-p+1}
\end{array}\right] ; c=\left[\begin{array}{c}
c \\
0 \\
\vdots \\
0
\end{array}\right] ; A=\left[\begin{array}{ccccc}
A_{1} & A_{2} & \ldots & A_{p-1} & A_{p} \\
I_{N} & 0 & \ldots & 0 & 0 \\
0 & I_{N} & 0 & 0 \\
\vdots & & \ddots & \vdots & \vdots \\
0 & 0 & \ldots & I_{N} & 0
\end{array}\right] ; U_{t}=\left[\begin{array}{c}
u_{t} \\
0 \\
\vdots \\
0
\end{array}\right] . \\
N \cdot p \times 1 \quad N \cdot p \times 1 \quad N \cdot p \times N \cdot p \times 1
\end{gathered}
$$

The Moving Average (MA) representation of this process is $y_{t}=\mu+\sum_{h=0}^{\infty} \Phi_{h} u_{t-h}$ with $\Phi_{h}=J A^{h} J^{\prime}$ and $J=\left[I_{N}: 0: \ldots: 0\right]$, which is a $N \times N \cdot p$ selection matrix (Lütkepohl 2007, pp. 15ff.). The coefficient matrices $\Phi_{h}$ contain the impact multipliers of the system. Their element $\phi_{i j, h}$ describes the response of the $i$ th asset range volatility to a shock in the $j$ th asset range volatility, $h$ periods ago. $\Phi_{j}(h)$ is the corresponding impulse response function.

The elements in $u_{t}$ are correlated and estimation of the coefficient matrix $\Phi_{h}$ requires external coefficient restrictions. One possibility is to orthogonalize the shocks, e.g., via a Cholesky decomposition of the covariance matrix $(\Sigma)$, such that the orthogonalized impulse response function traces the system's response to a specific ceteris paribus shock in the range of asset $j$ over time. But this makes impulse responses sensitive to the variable ordering in the VAR model (Enders 2010, p. 309). As we investigate volatility interactions within a system of different asset markets, such an order is difficult to impose and introduces an unwanted element of subjectivity into the estimation.

Generalized impulse responses are an alternative restriction method developed by Koop et al. (1996) and extended by Pesaran and Shin (1998). The generalized impulse response function is computed as $\Phi_{j}^{g}(h)=\sigma_{j j}^{-\frac{1}{2}} \Phi_{h} \Sigma e_{j}$, where $\sigma_{j j}$ is the variance of the error term in the equation for the $j$ th range volatility and $e_{j}$ is a $N \times 1$ selection vector containing 1 as its $j$ th element and is 0 otherwise (Pesaran and Shin 
1998). These impulse responses represent how the range of asset $i$ responds to a shock in the range of asset $j$, taking into account the contemporaneous correlations contained in $\Sigma$ (Pesaran and Pesaran 1997, p. 428). The impulse response function thus traces the system's response to a typical composite shock emanating from the range in asset $j$ (Pesaran and Shin 1998). The responses are independent of variable ordering and are therefore more suitable for use in an analysis of our asset market system. Pesaran and Shin (1998) calculated generalized FEVs $\left(\theta_{i j}^{g}\right)$ as:

$$
\theta_{i j}^{g}(h)=\frac{\sigma_{j j}^{-1} \sum_{l=0}^{h-1}\left(e_{i}^{\prime} \Phi_{l} \Sigma e_{j}\right)^{2}}{\sum_{l=0}^{h-1}\left(e_{i}^{\prime} \Phi_{l} \Sigma \Phi_{l}^{\prime} e_{i}\right)}, i, j=1,2, \ldots, N
$$

where the subscript $l$ denotes the respective forecast period. ${ }^{7}$ The correlated shocks lead to a non-diagonal $\Sigma$, and elements in the rows of the $\theta_{i j}^{g}$ matrix will not sum up to 1 .

\subsubsection{Volatility Spillover Indices}

Time-varying volatility spillover indices require a rolling estimation of the VAR(p) model. A regression window of size $w$ and $T$ observations for the range volatilities will give a total of $T-w+1$ estimates for the $\theta_{i j}^{g}$ matrices. For a system of $N$ assets, the elements off the main diagonal in the $\theta_{i j}^{g}$ matrices show the contributions of shocks to the range of assets $j=1, \ldots, N$ to the $h$-step ahead FEV for the range of assets $i=1, \ldots, N$, with $i \neq j$ and the diagonal elements denoting the contributions of own shocks. Analogous to the definitions as given by Diebold and Yilmaz (2012), a spillover is defined as the share of the contributions of shocks to the range of assets $j=1, \ldots N$ in relation to the total FEV of the range of assets $i$ with $i \neq j$. This constitutes the basis for the spillover index calculations.

First, the $\theta_{i j}^{g}$ matrices were normalized with the respective row sums such that the entries in each row sum up to $1 .{ }^{8}$ Consequently, the total FEV across the range for all assets in the system is equal to $N$. The definitions and formulas to calculate the individual spillover indices according to Diebold and Yilmaz (2012) are presented in Table 9.1.

\footnotetext{
${ }^{7}$ The typographical error in Pesaran and Shin (1998, pp. $20 \mathrm{ff}$.), where $\sigma_{i i}$ was used instead of $\sigma_{j j}$, as pointed out in Diebold and Yilmaz (2011, p. 6), has been corrected.

${ }^{8}$ As suggested in Diebold and Yilmaz (2012), it would also be possible to normalize with the column sums.
} 
Table 9.1 Volatility spillover indices

\begin{tabular}{|c|c|}
\hline \multicolumn{2}{|l|}{ Total spillover index (TOTAL) } \\
\hline $\begin{array}{l}\text { Sum of spillovers to the range across all asset classes in relation to } \\
\text { the total FEV in the system }\end{array}$ & $\begin{array}{l}\operatorname{TOTAL}(h)= \\
\frac{\sum_{\substack{i, j=1 \\
i \neq j}}^{N} \theta_{i j}^{g}(h)}{N} \times 100\end{array}$ \\
\hline \multicolumn{2}{|l|}{ Directional spillover index from all other assets (FROM) } \\
\hline $\begin{array}{l}\text { Spillovers received by the range of asset } i \text { from the range of all other } \\
\text { assets } j=1, \ldots, N, j \neq i \text {, in relation to the total FEV in the system }\end{array}$ & $\begin{array}{l}\operatorname{FROM}_{i}(h)= \\
\frac{\sum_{\substack{j=1 \\
j \neq 1}}^{N} \theta_{i j}^{g}(h)}{N} \times 100\end{array}$ \\
\hline \multicolumn{2}{|l|}{ Directional spillover index to all other assets (TO) } \\
\hline $\begin{array}{l}\text { Spillovers transmitted by the range of asset } i \text { to all other assets } \\
j=1, \ldots, N, j \neq i \text {, in relation to the total FEV in the system }\end{array}$ & 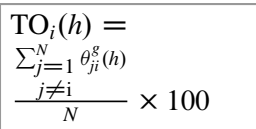 \\
\hline \multicolumn{2}{|l|}{ Net spillover index $(N E T)$} \\
\hline $\begin{array}{l}\text { Spillovers transmitted by the range of asset } i \text { to the range of all other } \\
\text { assets } j=1, \ldots, N, j \neq i \text { less spillovers received from the range of } \\
\text { all other assets } j=1, \ldots, N, j \neq i \text {, in relation to the total FEV in the } \\
\text { system }\end{array}$ & $\begin{array}{l}\operatorname{NET}_{i}(h)= \\
\operatorname{TO}_{i}(h)-\operatorname{FROM}_{i}(h)\end{array}$ \\
\hline \multicolumn{2}{|l|}{ Net pairwise spillover index (PAIR) } \\
\hline $\begin{array}{l}\text { Spillovers transmitted by the range of asset } i \text { to the range of one } \\
\text { specific asset } j, j \neq i \text {, less spillovers received from the range of this } \\
\text { asset } j \text {, in relation to the total FEV }\end{array}$ & $\begin{array}{l}\operatorname{PAIR}_{i j}(h)= \\
\left(\frac{\theta_{j i}^{g}(h)-\theta_{i j}^{g}(h)}{N}\right) \times 100\end{array}$ \\
\hline
\end{tabular}

\subsection{Empirical Results}

We calculated the assets' range volatilities (for detailed results, see Grosche and Heckelei 2014) and used them in the rolling VAR estimation, from which we computed the volatility spillover indices. We also discuss the results and relate the findings to the current literature.

\subsubsection{Rolling VAR Estimation and Spillover Index Calculation}

We used logged range volatilities and included a total of 3930 observations for each of the eight assets for a window length of 252 trading days. This reflects the volatility movements within one trading year and, at the same time, yields a sufficient number of observations to estimate the VAR. Lag length selection with the Schwartz Bayesian Criterion (SBC) yielded a VAR(5), and the FEV matrices were calculated for a forecast horizon of 10 days. The length of a forecast horizon depends on the underlying assumption regarding the time horizon of asset market 


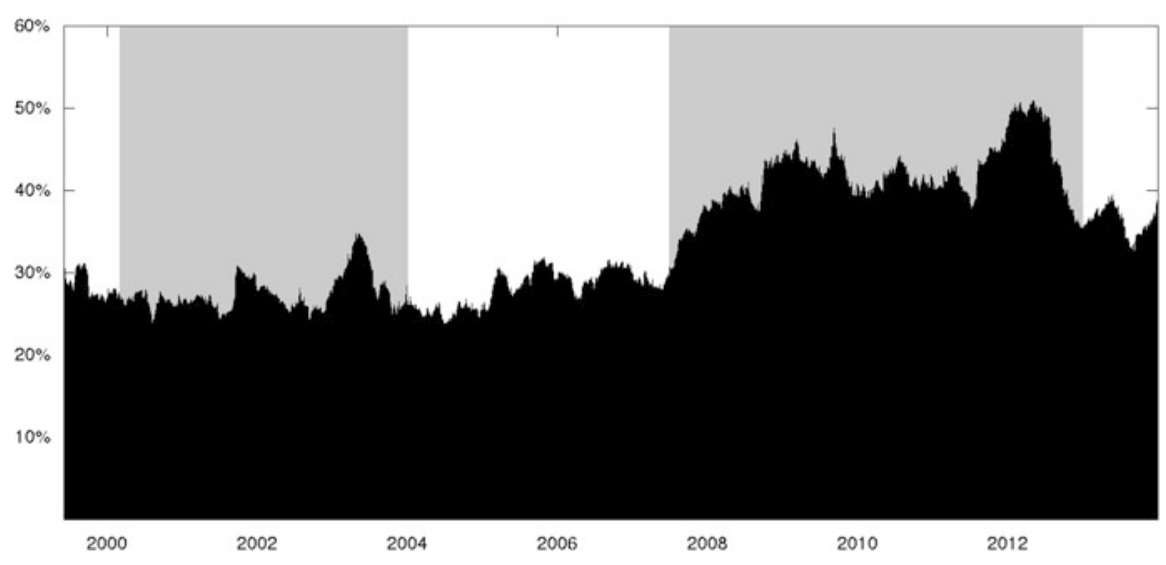

Fig. 9.1 Total volatility spillover index

linkages. A forecast horizon of 10 days is commonly used in calculating financial value at risk (Diebold and Yilmaz 2011). We obtained a total of 3679 observations for each spillover index, and the first observation corresponds to the end of the first regression window (2 June 1999). More details on the rolling VAR estimation, including verification of the robustness of the obtained results, are included in Grosche and Heckelei (2014).

Figure 9.1 shows the total volatility spillover index between 2 June 1999 and 31 December 2013. The areas shaded in gray mark the two major crisis periods of the last decade. The first period of crisis, between March 2000 and December 2003, was characterized by the burst of the dot.com bubble, the NASDAQ crash, and the overall downturn in equity markets. The real economy in the USA and the EU experienced low GDP growth rates. The events of September 11, 2001, and the wars in Afghanistan and Iraq led to political unrest. Agricultural commodity markets were influenced by (1) the continual efforts of the EU to reduce buffer stocks, (2) China's accession to the WTO in December 2001, and (3) growing US soybean exports.

The second period of crisis, between July 2007 and December 2012, started with the early events of the subprime crisis and transformed into a global liquidity crisis; it later evolved into a sovereign bond and state debt crisis. The US Federal Reserve Bank lowered interest rates 12 times successively between August 2007 and December 2008, and the real economy in the US and the EU was hit with low or even negative GDP growth rates. Agricultural commodity markets experienced further growth in soybean exports to China and were affected by the introduction of biofuel mandates in the EU and the USA. At the beginning of the period, the stock-to-use ratios for corn and wheat were at low levels of around $13 \%$ and $18 \%$ respectively, while the stock-to-use ratio for soybeans peaked at $21 \%$ (USDA ERS 2012). Commodity ETP assets under management strongly increased from 6.3 billion US dollars in 2007 to 45.7 billion US dollars in 2010 (BlackRock 2011). 

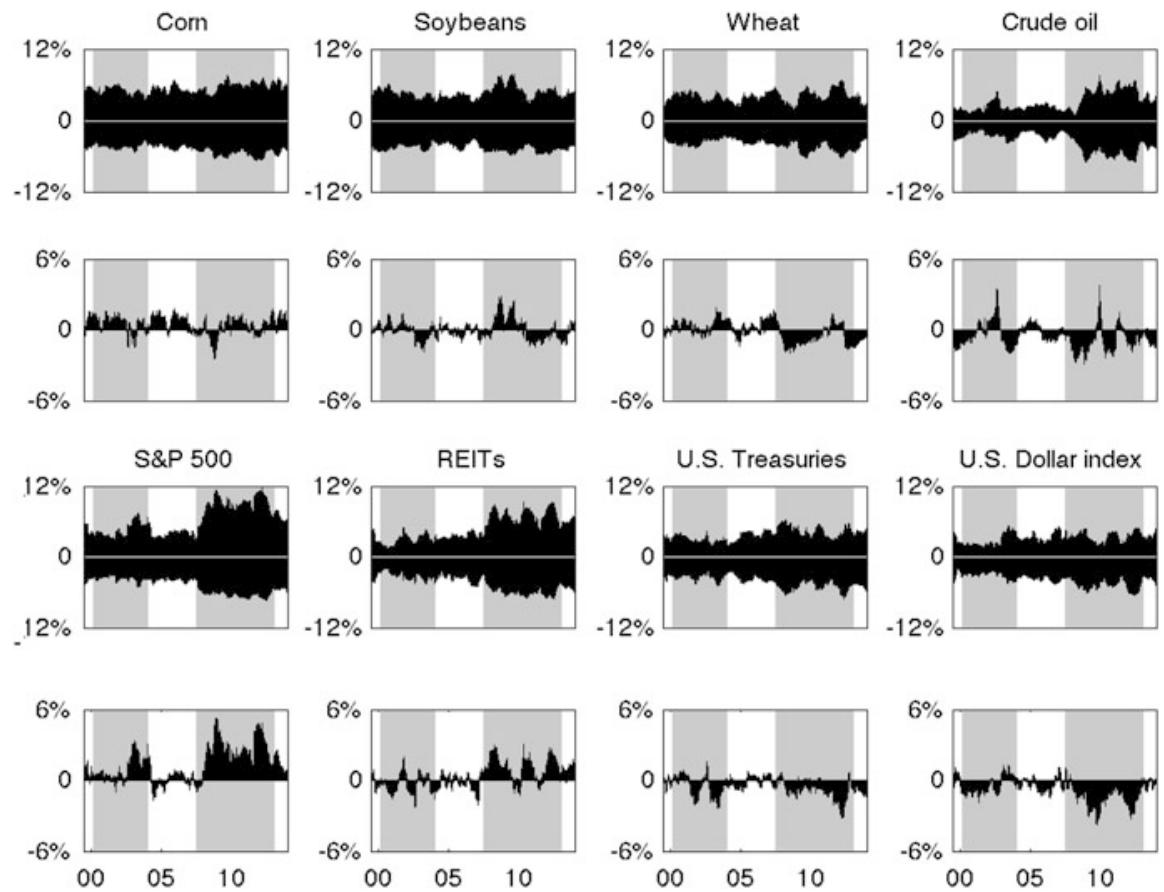

Fig. 9.2 Directional and net spillover indices. Note: The upper graphs in each pair show the spillovers from and to this asset compared to all other assets in the system. The lower graphs are the resulting net volatility spillover indices, where a positive (negative) value indicates that the asset is a net volatility transmitter (receiver)

Volatility spillovers were at much higher levels in the second period of crisis than the first. While there are two spikes in the first period of crisis $(31 \%$ in September 2001 and $35 \%$ in April 2003), the average total spillover between 1 March 2000 and 31 December 2003 amounted to $26 \%$. In comparison, the average total spillover between 1 July 2007 and 31 December 2012 was $42 \%$. The index peaked at $51 \%$ on 3 May 2012.

Directional spillovers and the resulting net spillover indices are depicted in Fig. 9.2. During the first crisis, neither of the commodity markets showed a distinct pattern and the indices moved almost horizontally into the tranquil interim period. Only crude oil and, to some extent, wheat futures have spiking directional volatility spillovers. Net spillovers from crude oil peaked at $3.4 \%$ in August 2002, and net spillovers from wheat at $1.8 \%$ in May 2003. In contrast, during the second crisis, volatility spillovers to and from the commodity markets were at higher levels; the net spillover patterns also differ from the previous periods. The changes in the magnitude of volatility spillovers to and from crude oil were, again, most pronounced. And, crude oil was mostly a net volatility receiver during most of the crisis period. Notable spillovers also occurred in wheat and soybean markets. The 
net volatility transmission from soybeans to other assets reached up to $2.9 \%$ in September 2008. Wheat markets were net volatility receivers and peaked at $1.9 \%$ in June 2008. Only corn market volatility spillovers appeared relatively unaffected by the crisis and showed only a slight increase in level.

Among the financial asset markets, the S\&P 500 is the largest net volatility transmitter in the system, with visible increases in the period of crisis (up to $3.4 \%$ in February 2003) and very pronounced peaks in the second crisis period (up to $5.3 \%$ in November 2008). In contrast, the US Treasuries and the US Dollar index were both volatility receivers during the two periods of crisis. Again, the effect was more pronounced in the second crisis, whereby net spillovers to the US Treasuries reach up to $3.2 \%$ in March 2012 and spillovers to the US Dollar index up to $3.7 \%$ in October 2009. The REITs market showed the biggest change in volatility interaction between the two crisis periods. While the REITs market alternated between being a net volatility transmitter and being a net volatility receiver during the first crisis, it almost unexceptionally transmits volatility to of up to $3 \%$ during the later crisis.

The pairwise spillover indices allow for the most detailed investigation of structural changes in volatility interaction between agricultural and energy commodities as well as between commodity and financial asset markets. ${ }^{9}$ Figure 9.3 shows the pairwise indices for the agricultural commodities. Over most of the observation period, corn was transmitting volatility to the soybean market at a general magnitude of between 3 and $6 \%$. There was no marked difference between the first crisis and the interim tranquil period. But during the second crisis, the volatility spillover relationship was reversed. Between 2008 and 2010, soybean markets were transmitting volatility of up to $7.5 \%$ to corn markets in September 2008. In parallel to this development, the volatility spillover relationship between soybeans and wheat also changed. Starting in 2008, soybeans became net transmitters of volatility to wheat, with a peak of $6 \%$ in June 2009 . Wheat was mostly a net volatility receiver from corn at a magnitude of up to $4.7 \%$ in September 2002 and $6.5 \%$ in January 2010. There were, however, exceptions occurring (1) towards the end of the first crisis, (2) shortly before the second crisis began, and, most importantly, (3) between 2010 and 2012, when wheat spillovers to corn reach up to $5.3 \%$ in February 2011.

Figure 9.4 shows the indices for the agricultural-crude oil pairs. Corn was transmitting volatility to crude oil during most of the tranquil period, before the first crisis (up to $5 \%$ in March 2000), and during the second crisis (up to $5.3 \%$ in July 2009). This relation was reversed and crude oil transmitted volatility to corn in the following two periods: (1) between November 2001 and January 2003, during the first crisis, and (2) after February 2011, during the second crisis; spillovers reached up to $6.1 \%$ in September 2002 (the first crisis) and 2.6\% in May 2011 (the second crisis). The soybean-crude oil volatility linkages almost perfectly mirrored this development. Soybeans mostly transmitted volatility to crude oil and received volatility of up to $5.2 \%$ in July 2002, during the early crisis, and

\footnotetext{
${ }^{9}$ Pairwise indices for financial asset markets cannot be discussed in detail in this chapter, but are available from the authors upon request.
} 

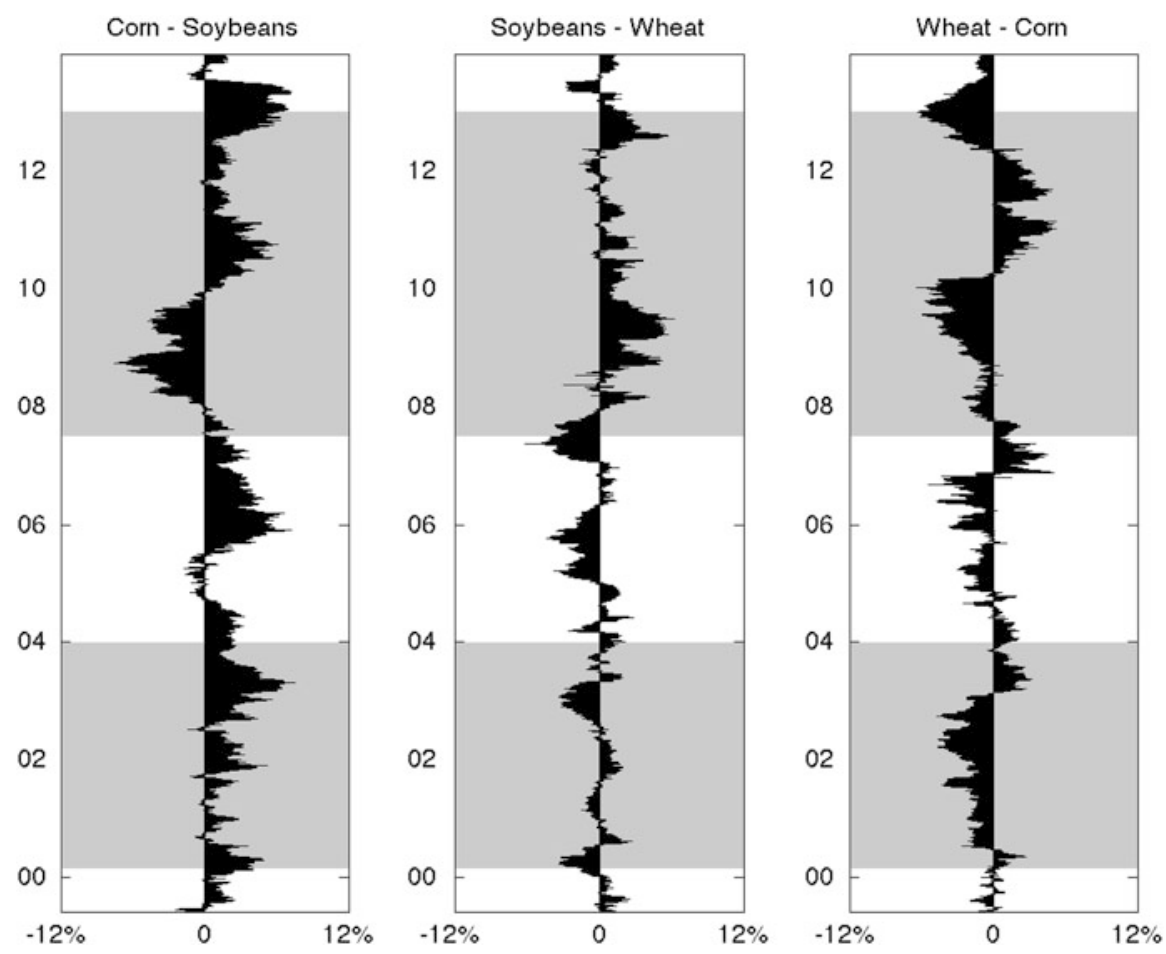

Fig. 9.3 Pairwise spillover indices: agricultural commodities

up to $4.5 \%$ in May 2011, during the later crisis period. While wheat was also mostly transmitting volatility to rather than receiving volatility from crude oil, the magnitude of interaction between the markets' volatility is generally lower than in the case of corn and soybeans. But there was one notable spillover spike of up to $12 \%$ in June 2003. And during the tranquil period, we observed some stronger spillovers from wheat to crude oil of up to $5.4 \%$ in June 2006.

Figure 9.5 shows the pairwise indices for the commodities and the financial asset markets. During the early crisis, volatility from the S\&P 500 predominantly spilled over into corn and wheat markets, with a high of $6.4 \%$ in February 2003 for corn and $4.3 \%$ in November 2002 for wheat. Soybean markets, in contrast, were mostly net transmitters of volatility to the S\&P 500 during that period. While crude oil markets received some spillovers, they also transmitted volatility to the S\&P 500 during November 2001 and October 2002, with a strong magnitude of up to $10.6 \%$ in August 2002. But during and after the second crisis, there was a notable change in this volatility spillover relationship, both in direction and in magnitude. Crude oil mostly received volatility from the S\&P 500, peaking at $10.8 \%$ in December 2010. A less pronounced but nevertheless visible change occurred in corn and wheat markets, whereby net spillovers from the S\&P 500 increased in magnitude around the time of the subprime crisis, with peaks of $5.3 \%$ in October 2008 for corn and of 

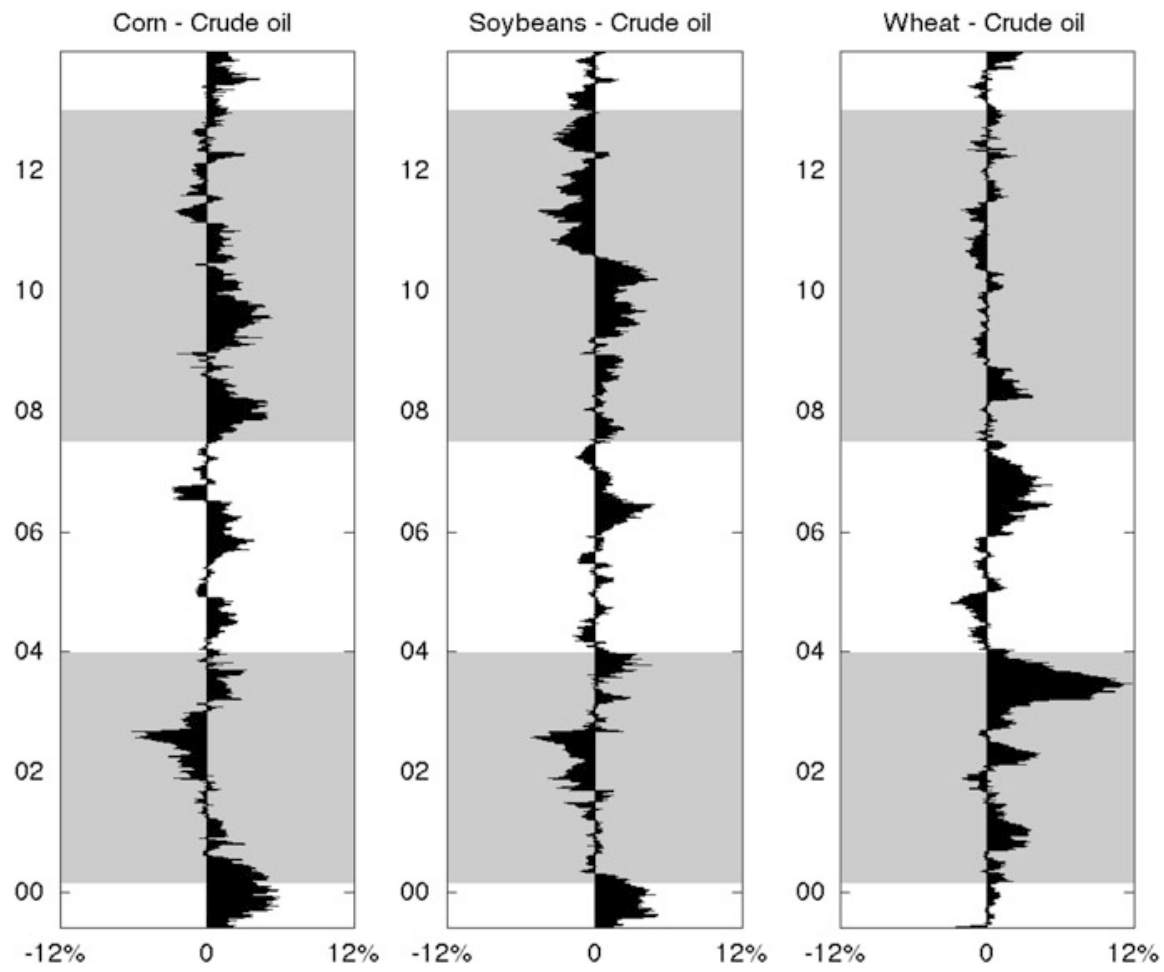

Fig. 9.4 Pairwise spillover indices: agriculture—crude oil

$6.7 \%$ in April 2008 for wheat. Soybean markets showed no change in the magnitude of spillover relationships, but in contrast to the crisis in the early 2000s, they became mostly net volatility receivers from the S\&P 500 .

While the REITs market was a net volatility transmitter to all commodities during parts of the first crisis, this tendency continued for most commodities (except soybeans) into the tranquil interim period. During the crisis, spillovers rose to $4.7 \%$ in January 2003 for corn, $3.8 \%$ in October 2001 for wheat, $4.7 \%$ in January 2003 for soybeans, and $4.5 \%$ in January 2002 for crude oil. For the agricultural commodities, there was no marked difference in spillover patterns during the later crisis. But, in parallel to the developments in the volatility relation with the $S \& P$ 500 , crude oil started to receive markedly higher net spillovers from the REITs market of up to $9.3 \%$ in February 2009. There was only a short period of reversed transmission between July 2009 and April 2010.

Net spillover between commodities and US Treasuries occurred bidirectionally during both the early crisis and the tranquil period. But there were some exceptions. Around December 2001, there was a period in which volatility of up to $7.2 \%$ spilled over from soybean markets into Treasuries. In the second crisis, corn and wheat markets were almost exclusively net receivers of volatility from the US Treasury 

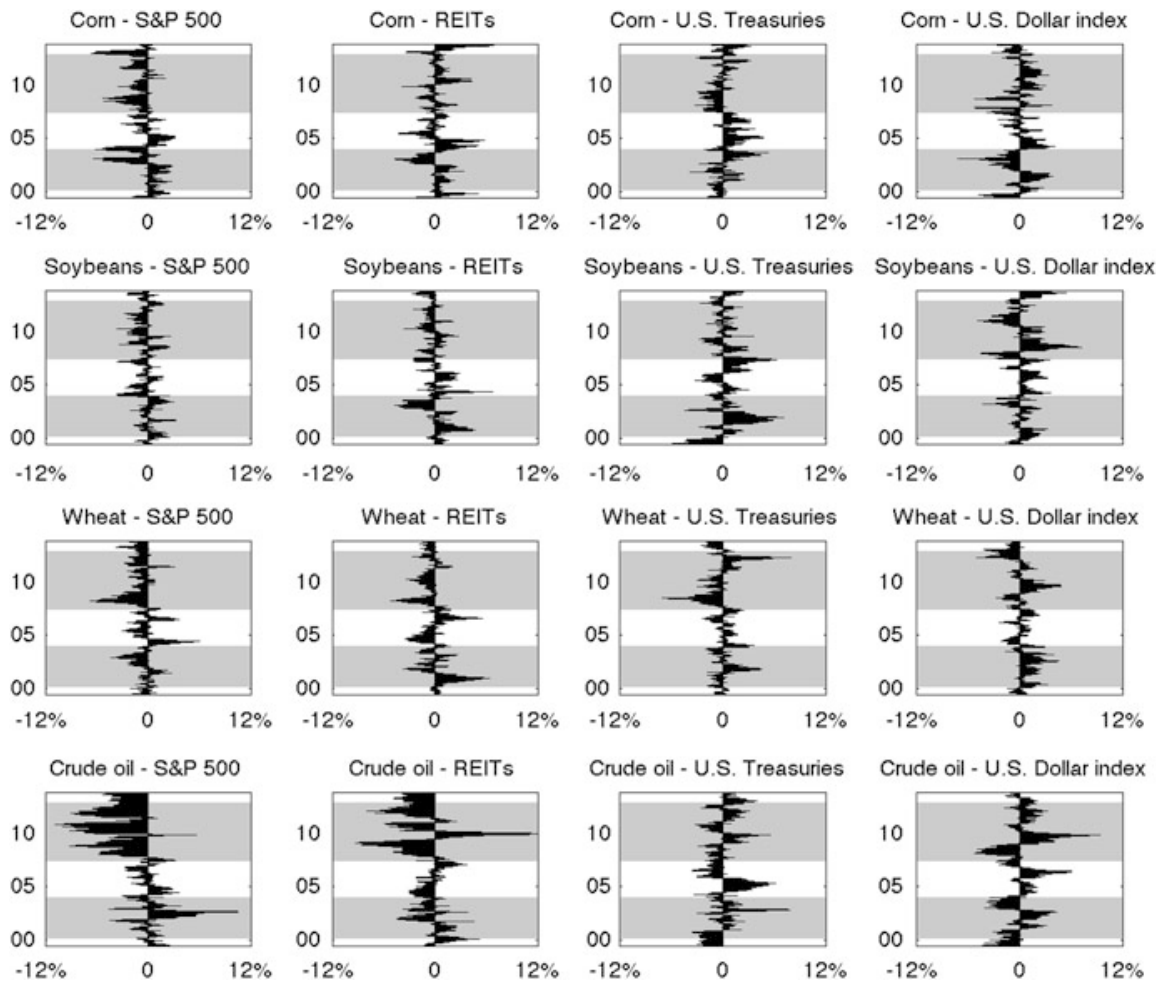

Fig. 9.5 Pairwise spillover indices: commodity—financial assets

(up to $3.2 \%$ in March 2008 for corn and $7 \%$ in July 2008 for wheat), while for soybeans and crude oil, the patterns were less distinct.

Towards the end of the first crisis, the US Dollar index transmitted volatility to the corn, soybean, and crude oil markets: up to $7.1 \%$ in February 2003 (corn), $4.3 \%$ in March 2003 (soybeans), and $4 \%$ in December 2002 (crude oil), while during almost the entire crisis period wheat was a net volatility transmitter to the index with a peak of $4.6 \%$ in August 2002. During the second crisis, however, soybeans, crude oil, and wheat markets transmitted net volatility to the US Dollar index: up to $7.2 \%$ in August 2008 (soybeans), $4.9 \%$ in September 2009 (wheat), and $9.4 \%$ in December 2009 (crude oil), while the net volatility transmission of corn markets was lower and had a less clear direction.

\subsubsection{Discussion of Results}

The analysis of the above volatility spillover indices does not permit any direct causal attribution of single spillovers. Nevertheless, it is interesting to examine the 
results in the light of the political and economic developments on the markets and in relation to existing empirical findings about volatility linkages.

The total volatility spillover index shows a distinct increase in range volatility interdependence between the markets during the second period of crisis. While the levels of individual range volatilities were also high at the height of the subprime crisis, the total spillover index peaked only in May 2012, when the volatility levels of individual markets decreased again. In comparison, during the first crisis, there were only two smaller volatility spillover spikes despite high volatility levels in some markets. Thus, over the course of the subprime crisis, the movements of individual volatilities became increasingly synchronized with each other, and they also experienced significant parallel jumps. On the other hand, the period of increased volatility interdependence stretched beyond the period of individual volatility jumps, pointing to a generally higher degree of market interaction.

Directional and net volatility spillover indices showed that the S\&P 500 was the strongest volatility transmitter among the assets during the financial crises. Thus, the drivers behind the S\&P 500 range volatility would likely also influence the range volatility in other markets. The magnitude of spillovers to and from the other financial asset markets was much lower. Although REITs are also a component of the S\&P 500, the stand-alone REITs spillover indices can better illustrate the volatility linkages during the subprime crisis, when REITs were strong net volatility transmitters and remained so until the end of the observation period. US Treasuries, in contrast, are traditionally refuge assets, towards which liquidity is shifted during general economic recessions and individual market crises (e.g., equity or real estate). This effect is visible on the spillover indices, whereby US Treasuries were net volatility receivers during both crisis periods. Unsurprisingly, net spillovers were especially high during the sovereign bond crisis at the end of the second crisis period. The US economy experienced an economic recession during both crisis periods, which affected demand for the US dollar. But the US dollar is also the most important currency for international monetary reserves. While the US Dollar index is a net volatility receiver during both crisis periods, the levels of spillovers increased in the second period, at a time when both the need to adjust monetary reserves and to allocate liquidity to comparably safer US Treasuries was high.

\subsubsection{Agricultural: Energy Linkages}

Corn appeared to be the strongest volatility transmitter among the agricultural commodities, with significant spillovers into both wheat and soybeans. This is plausible as (1) the USA is the world's largest producer of corn and a significant acreage area is allocated to growing corn, and (2) trading volumes of corn futures were much higher on the CBOT than of soybean and wheat futures. Therefore, information is most likely disseminated from corn markets to other affected futures markets rather than in the opposite direction. While seemingly unaffected by the early crisis, the corn-soybean relationship reversed between 2008 and 2010. During that time, soybeans also transmitted volatility to wheat. This effect could be related to China's surging demand for soybeans, which shocked the soybean market and also affected corn and wheat through substitution effects. 
The pairwise agriculture-energy spillover indices show that the magnitude of spillovers between both corn and soybeans and crude oil is higher than for wheat. The level of spillovers did not considerably change after 2006; therefore, this effect cannot be clearly attributed to biofuel production. In fact, the spillover indices do not yield any convincing evidence that an increase in spillovers from the energy to relevant commodity markets was a result of the biofuel mandates. While there were some spillovers from crude oil markets to both corn and soybeans markets in the first crisis, between 2006 and 2010, both markets transmitted volatility to crude oil rather than receive it. Only soybeans experienced a clear reversal in that relationship after 2010 .

These results are mostly in line with the findings of Gardebroek and Hernandez (2012), who, based on weekly conditional volatility over the period 1997-2011, did not discover evidence of energy volatility spilling over to corn price volatility. And while Ji and Fan (2012) did find significant linkages in the conditional daily volatility between crude oil and the crop index (which includes corn, wheat, soybeans, soft commodities, livestock, and cotton), they also found a decrease in spillovers during the subprime crisis. On the other hand, the results contradict the findings of, e.g., Nazlioglu et al. (2013), Du et al. (2011), and Chang and Su (2010). Using their respective models and volatility measures, they showed that volatility spillovers between crude oil and (1) corn, (2) wheat, and (3) soybeans increased after 2006. But Nazlioglu et al. (2013) also found bidirectional spillovers between (1) crude oil and soybeans and (2) crude oil and wheat after 2006, which is again closer to the results obtained from the spillover indices.

The extraordinary spike (up to $12 \%$ ) in the volatility spillovers from wheat into crude oil in June 2003 would merit a closer (causal) investigation. There could be some connection to the end of the UN Iraq oil-for-food program in 2003, which was used by the Iraqi government to secure wheat supplies in exchange for crude oil. It is interesting that Nazlioglu et al. (2013) also found Granger causality in variance from wheat to crude oil before 2005, but it could not be found after 2005 .

Thus, there is little indication that short-term daily range volatility linkages in the corn, soybean, and wheat markets were affected by biofuel policies. This is in contradiction to some findings derived using the GARCH-type models. The contradictions could stem from the choice of sample splits and restricting sample size to two or three markets. In this chapter, the volatility spillovers were calculated for a more comprehensive system of asset markets; some of the apparent bivariate volatility spillovers may be absorbed by other markets. Also, structural breaks were not exogenously imposed. Instead, more gradual structural changes were permitted.

\subsubsection{Commodity: Financial Linkages}

The linkages between commodity and financial markets vary strongly depending on the commodity and financial asset class involved. In the first crisis, there were few instances of S\&P 500 volatility spilling over to commodities, and the spillovers were low magnitude. However, there were some spillovers from crude oil into the S\&P 500, which could be explained in terms of fundamentals with the wars in Afghanistan and Iraq. Our findings thus lend strength to the results of Diebold 
and Yilmaz (2012), who speculated that the range volatility spillover between DJ UBS Commodity index and the S\&P 500 during that time were linked to the Iraq war. During and after the second crisis, however, all commodity markets were net S\&P 500 spillover receivers. This is again similar to and an extension of the findings in Diebold and Yilmaz (2012) about the DJ UBS Commodity index. Our results generated from data on individual commodity markets allowed for further disaggregation of the spillovers and showed that most net spillovers reached the crude oil market. Yet, corn and wheat also received some transitory spiking net spillovers. All commodities, and especially crude oil, have strong fundamental and financial linkages with US equities because they are inputs in production and components of all important commodity indices, in which crude oil is generally given higher weights than corn, soybeans, or wheat. An increase in short-term range volatility linkages was observed during a time when both commodity index-linked products became more widespread and commodity trading volume increased. This provided evidence in favor of the hypothesis that the financial linkage factor became more important in the second crisis period.

Our results lend strength to the existing results about volatility linkages between the S\&P 500 and commodities. Mensi et al. (2013) have shown that volatility shocks to the S\&P 500 can significantly affect the oil market; the results of their study are also confirmed for range volatility spillovers. Gao and Liu (2014) found that correlations between energy and grains indices and the S\&P 500 increase in periods of volatility, which is also in line with the results above. But, in their model, US energy indices and grains indices did not frequently share common volatility regimes with the S\&P 500, and this led the authors to conclude that commodities remain an attractive portfolio diversifier. Yet, the spillover indices show stronger volatility relationships, especially between the S\&P 500 and crude oil, which may in fact decrease diversification benefits. In addition, our results for spillovers complement the evidence of increased dynamic conditional return correlations between commodities and the S\&P 500 during and after 2008 (e.g., Huang and Zhong 2013; Bicchetti and Maystre 2013; Büyükşahin et al. 2010). The observation made by Creti et al. (2013) that oil-S\&P 500 return correlations increase with increasing stock prices could not be confirmed for daily range volatility spillovers (rather, it increase with decreasing stock prices).

The fundamental connection between REITs and commodity markets is much weaker than the connection between commodities and the S\&P 500. Nevertheless, volatility spillovers from REITs into crude oil were high in the early 2000s and surged in the late 2000s crisis. This provides additional evidence in favor of the financial linkage hypothesis. But agricultural commodities appear to have much weaker linkages to REITs markets. Volatility spillovers between commodities and US REITs have barely been analyzed in the literature. Somewhat related to our results, Huang and Zhong (2013) showed that commodities and REITs (along with inflation-protected securities) each offer unique diversification benefits that tend to disappear during a financial crisis. 
In contrast to the S\&P 500 and REITs, the magnitude of range volatility spillovers between commodities and US Treasuries generally appears unaffected by either of the crisis periods. This confirms results of Huang and Zhong (2013), who also found that conditional correlations between the S\&P GSCI and US Treasuries did not significantly increase during the subprime crisis. The net spillovers from the DJ UBS Commodity index to US Treasuries identified by Diebold and Yilmaz (2012) were further disaggregated in our model, and they appear to stem mostly from crude oil and soybeans as both wheat and corn markets are net receivers of volatility from US Treasuries during that period.

The US Dollar index receives net volatility spillovers from wheat, soybeans, and crude oil during both crisis periods. But spillovers increased in magnitude during the late 2000s crisis. This could be related to China importing more soybeans and crude oil and the associated changes in the demand for the US dollar. Another explanation is foreign activities on US commodity futures markets. The corn-US Dollar index relationship is less clear, and during the second crisis period, corn transmits less volatility to the US Dollar index than the other commodities. Linkages could have decreased following the drop in US corn exports. Corn was increasingly used for the domestic biofuel production in the USA. The findings of Diebold and Yilmaz (2012) about the spillovers between the DJ UBS Commodity index and the US Dollar index are substantiated for most individual commodities, and crude oil does not appear to be the main driver of the spillover. Ji and Fan (2012) found that volatility spillovers from the US Dollar index to the CRB crop index became weaker after the subprime crisis. When compared with the respective volatility spillover indices, their results only match the ones for corn but not that for soybeans or wheat.

\subsection{Conclusions}

This chapter has investigated directional time-varying range volatility spillovers using a new method developed by Diebold and Yilmaz $(2009,2012)$. The chapter focuses on short-term volatility interaction effects within a system which comprises agricultural products, crude oil, and selected financial asset markets over the period between 3 June 1998 and 31 December 2013. We especially emphasized the comparison between the two periods of financial and economic crises, whereby the later crisis period is also characterized by an increased use of commodities as financial investment.

During and after the subprime crisis, individual range volatilities moved increasingly in synchrony, with significant parallel jumps. Also, the total volatility spillover index shows stronger volatility interdependence. This suggests an overall higher degree of market interaction. The S\&P 500 was the strongest net volatility transmitter in the system and spillovers peaked during the crisis periods. REITs net volatility transmission starts to rise only with the beginning of the subprime crisis. 
The pairwise agriculture-energy volatility spillover indices do not provide significant evidence for an increase in spillovers from the energy to relevant commodity markets as a consequence of biofuel mandates. While this is in line with the findings of some previous studies, such as Gardebroek and Hernandez (2012), it stands in contrast to the results of other related studies. This discrepancy could be because (1) the index uses the full sample rolling approach instead of exogenously introducing structural breaks and (2) the system was extended to include financial assets that could have absorbed some of the volatility spillovers. Yet, our results do not permit the conclusion that biofuel mandates did not have any effects on the volatility (or return) relation between crude oil and biofuel crops. Due to the focus on short-term range volatility, we did not capture any longer-term structural changes arising from events such as reallocating land to be used for biofuel crops as a consequence of a high or volatile oil price.

The pairwise commodity-financial volatility spillover indices show that the volatility interaction between commodity and US Treasury markets appeared relatively unaffected by the crisis periods, but spillovers from commodities to the US Dollar index increased (except in the case of corn). Yet, the most profound shift in volatility interaction occurred between the S\&P 500, US REITs, and commodity markets. Crude oil received high net spillovers from both financial asset markets during and after the second period of crisis. Agricultural commodities are less affected than crude oil, although there were some spikes in the spillovers into corn and wheat markets during the second crisis.

The volatility spillover patterns into and from commodities observed in the second period of crisis were more apparent than in the first crisis. While it is not possible to directly attribute causes to the discrepancy, the results do provide evidence in favor of the hypothesis that there were increased financial linkages between the markets. There are two important implications: First, shocks to financial asset markets, which have no direct fundamental connections to commodity markets, may increasingly affect short-term commodity market volatility. Second, if commodities find themselves increasingly being used as portfolio diversifiers and refuge assets, their diversification benefits may be reduced, especially in times of crisis.

Thus, future research should be directed towards investigating the underlying structural relationships behind the volatility linkages. And, as also suggested by Diebold and Yilmaz (2012), a theoretical and empirical comparison of the spillover indices with multivariate GARCH models could be useful. The focus should be put on the relationship between short-term conditional volatility and range volatility. A starting point could be the range volatility-based GARCH models such as the E-GARCH model used in Brandt and Jones (2006) and the conditional autoregressive range model used in Chiang and Wang (2011). In any case, the volatility spillover indices are a useful addition to the hitherto GARCH-centered analysis of volatility relationships. The indices should be further used to investigate alternative asset systems. 
Acknowledgments The authors thank Matthias Kalkuhl, Carlos Martins-Filho, Christian Schlag, and the participants of the IATRC annual conference, San Diego, California, December 2012, and the ZEF/IFPRI international expert consultation on food price volatility and food security, Bonn, Germany, January/February 2013.

Open Access This chapter is distributed under the terms of the Creative Commons AttributionNoncommercial 2.5 License (http://creativecommons.org/licenses/by-nc/2.5/) which permits any noncommercial use, distribution, and reproduction in any medium, provided the original author(s) and source are credited.

The images or other third party material in this chapter are included in the work's Creative Commons license, unless indicated otherwise in the credit line; if such material is not included in the work's Creative Commons license and the respective action is not permitted by statutory regulation, users will need to obtain permission from the license holder to duplicate, adapt or reproduce the material.

\section{References}

Alizadeh S, Brandt MW, Diebold FX (2002) Range-based estimation of stochastic volatility models. J Financ 57(3):1047-1091

Ankrim EM, Hensel CR (1993) Commodities in asset allocation: a real-asset alternative to real estate? Financ Anal J 49(3):20-29

Anson MJ (1999) Maximizing utility with commodity futures diversification. J Portfolio Manag 25(4):86-94

Beber A, Brandt MW, Kavajecz KA (2007) Flight-to-quality or flight- to-liquidity? Evidence from the Euro-Area bond market. Rev Financ Stud 22(3):925-957

Bicchetti D, Maystre N (2013) The synchronized and long-lasting structural change on commodity markets: evidence from high-frequency data. Algorithm Financ 2(3-4):233-239

BlackRock (2011) ETF landscape: global handbook. Q1, 2011

Bodie Z, Rosansky VI (1980) Risk and return in commodity futures. Financ Anal J 36(3):27-39

Brandt MW, Jones CS (2006) Volatility forecasting with range-based EGARCH models. J Bus Econ Stat 24(4):470-486

Büyükşahin B, Haigh MS, Robe MA (2010) Commodities and equities-ever a market of one? J Altern Invest 12(3):76-95

Chan KF, Treepongkaruna S, Brooks R, Gray S (2011) Asset market linkages: evidence from financial, commodity and real estate assets. J Bank Financ 35(6):1415-1426

Chang T-H, Su H-M (2010) The substitutive effect of biofuels on fossil fuels in the lower and higher crude oil price periods. Energy 35(7):2807-2813

Cheung Y, Ng LK (1996) A causality-in-variance test and its application to financial market prices. J Econ 72:33-48

Chiang M-H, Wang L-M (2011) Volatility contagion: a range-based volatility approach. J Econ 165(2):175-189

Chong J, Miffre J (2010) Conditional correlation and volatility in commodity futures and traditional asset markets. J Altern Invest 12(3):61-75

Commodity Futures Trading Commission (CFTC) (2013) Commitment of traders report. Historical compressed 2000-2012

Conover CM, Jensen GR, Johnson RR, Mercer JM (2010) Is now the time to add commodities to your portfolio? J Invest 19(3):10-19

Creti A, Joëts M, Mignon V (2013) On the links between stock and commodity markets' volatility. Energy Econ 37:16-28

Daskalaki C, Skiadopoulos G (2011) Should investors include commodities in their portfolios after all? New evidence. J Bank Financ 35(10):2606-2626 
Diebold FX, Yilmaz K (2009) Measuring financial asset return and volatility spillovers, with application to global equity markets. Econ J 119(534):158-171

Diebold FX, Yilmaz K (2011) On the network topology of variance decompositions: measuring the connectedness of financial firms. NBER working paper series. Working paper 17490

Diebold FX, Yilmaz K (2012) Better to give than to receive: predictive directional measurement of volatility spillovers. Int J Forecast 28(1):57-66

Du X, Yu CL, Hayes DJ (2011) Speculation and volatility spillover in the crude oil and agricultural commodity markets: a Bayesian analysis. Energy Econ 33:497-503

Enders W (2010) Applied econometric time series, 3rd edn. Wiley, Hoboken, NJ

Engle RF, Gallo GM (2006) A multiple indicators model for volatility using intra-daily data. J Econ 131(1-2):3-27

Fortenbery TR, Hauser RJ (1990) Investment potential of agricultural futures contracts. Am J Agric Econ 72(3):721-726

Gao L, Liu L (2014) The volatility behavior and dependence structure of commodity futures and stocks. J Future Mark 34(1):93-101

Gardebroek K, Hernandez MA (2012) Do energy prices stimulate food price volatility? Examining volatility transmission between U.S. oil, ethanol and corn markets. In: Selected paper prepared for presentation at the agricultural and applied economics association's 2012 annual meeting, Seattle, Washington, 12-14 Aug 2012

Gorton G, Rouwenhorst KG (2006) Facts and fantasies about commodity futures. Financ Anal J 62(2):47-68

Greer RJ (2007) The role of commodities in investment portfolios. CFA Inst Conf Proc Q 24(4):1-11

Grosche S-C, Heckelei T (2014) Directional volatility spillovers between agricultural, crude oil, real estate and other financial markets. ILR food and resource economics discussion paper 2014,4

Harri A, Hudson D (2009) Mean and variance dynamics between agricultural commodity prices and crude oil prices. In: Paper prepared for presentation at the economics of alternative energy sources and globalization: the road ahead meeting, Orlando, FL, 15-17 Nov 2009

Huang J-Z, Zhong Z (2013) Time variation in diversification benefits of commodity, REITs, and TIPS. J Real Estate Financ Econ 46:152-192

Jensen GR, Johnson RR, Mercer JM (2002) Tactical asset allocation and commodity futures. J Portf Manag 28(4):100-111

Ji Q, Fan Y (2012) How does oil price volatility affect non-energy commodity markets. Appl Energy 89:273-280

Koop G, Pesaran M, Potter SM (1996) Impulse response analysis in nonlinear multivariate models. J Econ 74(1):119-147

Lütkepohl H (2007) New introduction to multiple time series analysis, 1st ed, corr. 2nd print edn. Springer, Berlin

Mensi W, Beljid M, Boubaker A, Managi S (2013) Correlations and volatility spillovers across commodity and stock markets: linking energies, food and gold. Econ Model 32:15-22

Nazlioglu S, Erdem C, Soytas U (2013) Volatility spillover between oil and agricultural commodity markets. Energy Econ 36:658-665

Parkinson M (1980) The extreme value method for estimating the variance of the rate of return. J Bus 53:61-65

Pesaran M, Pesaran B (1997) Working with Microfit 4.0 - interactive econometric analysis. Oxford University Press, Oxford

Pesaran HH, Shin Y (1998) Generalized impulse response analysis in linear multivariate models. Econ Lett 58(1):17-29

Satyanarayan S, Varangis P (1996) Diversification benefits of commodity assets in global portfolios. J Invest 5(1):69-78

Silvennoinen A, Thorp S (2013) Financialization, crisis and commodity correlation dynamics. J Int Financ Mark Inst Money 24:42-65 
Trujillo-Barrera A, Mallory ML, Garcia P (2011) Volatility spillovers in the U.S. crude oil corn and ethanol markets. In: Proceedings of the NCCC-134 conference on applied commodity price analysis, forecasting and market risk management, St. Louis, MO

USDA ERS (2012) Agricultural baseline database 